\title{
Editorial: Wheeled Mobility Biomechanics
}

\author{
Philip Santos Requejo ${ }^{*}$ and Jill L. McNitt-Gray ${ }^{2,3}$ \\ ${ }^{1}$ Rehabilitation Engineering, Rancho Los Amigos National Rehabilitation Center, Downey, CA, USA, ${ }^{2}$ Biomechanics Research \\ Laboratory, Department of Biological Sciences, University of Southern California, Los Angeles, CA, USA, ${ }^{3}$ Biomechanics \\ Research Laboratory, Department of Biomedical Engineering, University of Southern California, Los Angeles, CA, USA
}

Keywords: wheelchair, mobility, shoulder, pain, spinal cord injuries, propulsion, car transfer, ultrasonography

\section{The Editorial on the Research Topic}

\section{Wheeled Mobility Biomechanics}

For the manual wheelchair (MWC) user, loss of lower extremity function often places the burden for mobility and activities of daily living on the upper extremities. People who use a MWC commonly report fatigue and musculoskeletal pain in the shoulder, most often due to increased demands of mobility (Kemp and Mosqueda, 2004; Kemp, 2005). Because individuals who rely on MWC are dependent on their upper extremities for mobility and requisite activities (sitting, transfers, and pressure reliefs), as well as activities initiated from the wheelchair (exercise, reaching, and lifting), shoulder pain and dysfunction (Vissers et al., 2008; Mulroy et al., 2011a) can limit independence and functional mobility (Gerhart et al., 1993; Pentland and Twomey, 1994; Ballinger et al., 2000; McCasland et al. 2006) and negatively impact community participation and quality of life (Gutierrez et al., 2007; Chang et al., 2012). While the exact relationship between the physical demands of wheelchair use and the development of shoulder pathology is not yet fully understood, ergonomics studies consistently suggest that there is a link between highly repetitive tasks and the occurrence of upper extremity pain and injury (Frost et al., 2002; Silverstein et al., 2008). Therefore, to prevent further loss of independence and functional mobility, it is imperative to find ways to preserve shoulder function for the MWC user.

In preparing for this Research Topic in Wheeled Mobility Biomechanics, we were particularly interested in receiving contributions about current research that provided insights into the mechanical demands and performance techniques during tasks associated with MWC use in order to gain a greater insight into upper extremity loading consequences, predictors of pain onset and injury, and identifying strategies that can preserve functional mobility for the MWC user.

In organizing the Research Topic issue, we invited a number of experts who study wheeled mobility from different perspectives with the intent of advancing the knowledge regarding the variables that promote or hinder an individual's capacity to handle the daily manual wheeled mobility demands. This is highlighted in the contribution by Gil-Agudo and colleagues who provided insights into the acute changes to the shoulder's soft tissues by evaluating the echographic and kinetic changes in the shoulder joint after MWC propulsion under two different workload settings (Gil-Agudo et al.). Zhao and colleagues presented an analysis of the scapular motion in three common tasks performed by individuals who use a MWC to gain insights into potentially detrimental shoulder kinematics experienced during wheelchair use and related activities (Zhao et al.). To provide a comprehensive approach for MWC prescription, training, and long-term care for children who use a MWC, Slavens and colleagues characterized the upper extremity biomechanics of MWC mobility in children and adolescents during propulsion, starting, and stopping (Slavens et al.). They identified the greatest demand occurring during the starting task, with distinct propulsion patterns that were unlike those seen in adults. 
Manual wheelchair Propulsion (WCP) technique is one aspect of wheelchair use that is believed to be associated with upper limb overuse injury (Boninger et al., 2002). Two contributions provided excellent insights into the relationship between propulsion technique and upper limb biomechanics (Dysterheft et al.). First, Dysterheft and colleagues studied the changes in adolescents' WCP biomechanics pre- and post-video and verbal feedback in order to maximize contact angle, while minimizing stroke frequency at the handrim (Paralyzed Veterans of America Consortium for Spinal Cord Medicine, 2005). Second, to gain insights into the relationship between WCP technique and loading consequences, Russell et al. showed how individuals with paraplegia modify WCP biomechanics to accommodate expected increases in reaction forces generated at the pushrim with selfselected increases in WCP speed.

There is growing theoretical and empirical evidence that fluctuations in movement (i.e., motor variability), including asymmetry between each arm during WCP, are related to musculoskeletal pain. In a perspective paper, Sosnoff and colleagues argue that the variability of WCP is impacted by shoulder pain and recommend inclusion of variability metrics can yield insights into shoulder pain development (Sosnoff et al.). Also, drawing from a large sample size, Soltau et al. establish the validity of bilateral symmetry during MWC propulsion in those without significant upper extremity pain or impairment.

For the MWC user, being able to self-transfer is essential for independence and community participation. But independent transfer, particularly car transfer, is complex, physically demanding, and known to provoke shoulder pain (Fliess-Douer et al., 2012). To gain insights into the relationship between movement technique and shoulder loading in activities associated with MWC use, Haubert and colleagues described techniques and factors influencing car transfer and WC loading for individuals with paraplegia driving their own vehicles and using their personal MWC (Haubert et al.). They provide an evidence-based recommendation for safe and effective car transfer technique for maintaining independence and preserving mobility for the MWC user.

We claim that creation and application of evidence-based strategies aimed at preserving shoulder function must be personalized and must address multiple factors related to ergonomics and equipment selection, performance techniques, and load-bearing capability of the individual. These include recommendations for reducing the mechanical loads and muscular demands through

\section{REFERENCES}

Ballinger, D. A., Rintala, D. H., and Hart, K. A. (2000). The relation of shoulder pain and range-of-motion problems to functional limitations, disability, and perceived health of men with spinal cord injury: a multifaceted longitudinal study. Arch. Phys. Med. Rehabil. 81, 1575-1581. doi:10.1053/apmr.2000.18216

Boninger, M. L., Souza, A. L., Cooper, R. A., Fitzgerald, S. G., Koontz, A. M., and Fay, B. T. (2002). Propulsion patterns and pushrim biomechanics in manual wheelchair propulsion. Arch. Phys. Med. Rehabil. 83, 718-723. doi:10.1053/ apmr.2002.32455

Chang, F.-H., Wang, Y.-H., Jang, Y., and Wang, C.-W. (2012). Factors associated with quality of life among people with spinal cord injury: application of the ergonomics, wheelchair selection and configuration, and environmental adaptations and personal factors for increasing the capacity to handle the daily mobility demands (Requejo et al., 2008, 2015). By integrating up-to-date knowledge of the musculoskeletal system, individual's capacity to generate and withstand external demands, preferred multijoint control strategies including propulsion technique, and repetitive load exposure through biomechanical modeling and simulations, feasible interventions can be identified and implemented (Munaretto et al., 2012, 2013; Slowik et al., 2015, 2016a,b).

In practice, we highlight the need for individualization of the wheelchair prescription process such that the characteristics of the wheelchair matched the functional capacity of the individual. Individually configured MWCs and seating systems can change postural alignment that improves comfort by decreasing pain from poor posture and improves the ability and efficiency to selfpropel, prolonging mobility and endurance and preventing the development of secondary problems. An appropriate wheelchair and seating system provides a stable base for using upper and lower extremities for all mobility-related daily activities and, most important, propelling a wheelchair to maintain independent functional mobility to maximize quality of life. What is important is that clinicians must identify the wheelchair characteristics that are crucial for each individual and then identify the appropriate wheelchair that results in a fit that is specific and unique to a single MWC user. The ability to prescribe, order, modify, or configure the frame or components, to achieve a final system that meets the medical and functional needs of the individual, remains a key ingredient for preserving wheeled mobility.

\section{AUTHOR CONTRIBUTIONS}

Drs. PR and JM-G contributed equally to the writing of the contents of this editorial.

\section{FUNDING}

Some contents of this article were developed under a grant from the US Department of Health and Human Services, Administration for Community Living, National Institute on Disability, Independent Living, and Rehabilitation Research (NIDILRR). However, these contents do not necessarily represent the policy of the Department of Health and Human Services, and you should not assume endorsement by the Federal Government.

international classification of functioning, disability and health model. Arch Phys. Med. Rehabil. 93, 2264-2270. doi:10.1016/j.apmr.2012.06.008

Fliess-Douer, O., Vanlandewijck, Y. C., and Van der Woude, L. H. (2012). Most essential wheeled mobility skills for daily life: an international survey among paralympic wheelchair athletes with spinal cord injury. Arch. Phys. Med. Rehabil. 93, 629-635. doi:10.1016/j.apmr.2011.11.017

Frost, P., Bonde, J. P., Mikkelsen, S., Andersen, J. H., Fallentin, N., Kaergaard, A., et al. (2002). Risk of shoulder tendinitis in relation to shoulder loads in monotonous repetitive work. Am. J. Ind. Med. 41, 11-18. doi:10.1002/ajim.10019

Gerhart, K. A., Bergstrom, E., Charlifue, S. W., Menter, R. R., and Whiteneck, G. G. (1993). Long-term spinal cord injury: functional changes over time. Arch. Phys. Med. Rehabil. 74, 1030-1034. doi:10.1016/0003-9993(93)90057-H 
Gutierrez, D. D., Thompson, L., Kemp, B., and Mulroy, S. J. (2007). The relationship of shoulder pain intensity to quality of life, physical activity, and community participation in persons with paraplegia. J. Spinal. Cord. Med. 30, 251-255.

Kemp, B. J. (2005). What the rehabilitation professional and the consumer need to know. Phys. Med. Rehabil. Clin. N. Am. 16, 1-18, vii. doi:10.1016/j. pmr.2004.06.009

Kemp, B. J., and Mosqueda, L. (2004). Aging with a Disability: What the Clinician Needs to Know. Baltimore: JHU Press.

McCasland, L. D., Budiman-Mak, E., Weaver, F. M., Adams, E., and Miskevics, S. (2006). Shoulder pain in the traumatically injured spinal cord patient: evaluation of risk factors and function. J. Clin. Rheumatol. 12, 179-186. doi:10.1097/01. rhu.0000230532.54403.25

Mulroy, S. J., Winstein, C. J., Kulig, K., Beneck, G. J., Fowler, E. G., DeMuth, S. K., et al. (2011a). Secondary mediation and regression analyses of the PTClinResNet database: determining causal relationships among the International Classification of Functioning, Disability and Health levels for four physical therapy intervention trials. Phys. Ther. 91, 1766-1779. doi:10.2522/ ptj.20110024

Munaretto, J. M., McNitt-Gray, J. L., Flashner, H., and Requejo, P. S. (2012). Simulated effect of reaction force redirection on the upper extremity mechanical demand imposed during manual wheelchair propulsion. Clin. Biomech. (Bristol, Avon) 27, 255-262. doi:10.1016/j.clinbiomech.2011.10.001

Munaretto, J. M., McNitt-Gray, J. L., Flashner, H., and Requejo, P. S. (2013). Reconfiguration of the upper extremity relative to the pushrim affects load distribution during wheelchair propulsion. Med. Eng. Phys. 35, 1141-1149. doi:10.1016/j.medengphy.2012.12.002

Paralyzed Veterans of America Consortium for Spinal Cord Medicine. (2005). Preservation of upper limb function following spinal cord injury: a clinical practice guideline for health-care professionals. J. Spinal Cord Med. 28, 434-470.

Pentland, W. E., and Twomey, L. T. (1994). Upper limb function in persons with long term paraplegia and implications for independence: part II. Paraplegia 32, 219. doi:10.1038/sc.1994.41

Requejo, P., Mulroy, S., Haubert, L. L., Newsam, C., Gronley, J., and Perry, J. (2008). Evidence-based strategies to preserve shoulder function in manual wheelchair users with spinal cord injury. Top. Spinal Cord Inj. Rehabil. 13, 86-119. doi:10.1310/sci1304-86

Requejo, P. S., Furumasu, J., and Mulroy, S. J. (2015). Evidence-based strategies for preserving mobility for elderly and aging manual wheelchair users. Top. Geriatr. Rehabil. 31, 26-41. doi:10.1097/TGR.0000000000000042

Silverstein, B. A., Bao, S. S., Fan, Z. J., Howard, N., Smith, C., Spielholz, P., et al. (2008). Rotator cuff syndrome: personal, work-related psychosocial and physical load factors. J. Occup. Environ. Med. 50, 1062-1076. doi:10.1097/ JOM.0b013e31817e7bdd

Slowik, J. S., McNitt-Gray, J. L., Requejo, P. S., Mulroy, S. J., and Neptune, R. R. (2016a). Compensatory strategies during manual wheelchair propulsion in response to weakness in individual muscle groups: a simulation study. Clin. Biomech. (Bristol, Avon) 33, 34-41. doi:10.1016/j.clinbiomech.2016.02.003

Slowik, J. S., Requejo, P. S., Mulroy, S. J., and Neptune, R. R. (2015). The influence of speed and grade on wheelchair propulsion hand pattern. Clin. Biomech. (Bristol, Avon) 30, 927-932. doi:10.1016/j.clinbiomech.2015.07.007

Slowik, J. S., Requejo, P. S., Mulroy, S. J., and Neptune, R. R. (2016b). The influence of wheelchair propulsion hand pattern on upper extremity muscle power and stress. J. Biomech. 49, 1554-1561. doi:10.1016/j.jbiomech.2016.03.031

Vissers, M., van den Berg-Emons, R., Sluis, T., Bergen, M., Stam, H., and Bussmann, H. (2008). Barriers to and facilitators of everyday physical activity in persons with a spinal cord injury after discharge from the rehabilitation centre. J. Rehabil. Med. 40, 461-467. doi:10.2340/16501977-0191

Conflict of Interest Statement: The authors declare that the research was conducted in the absence of any commercial or financial relationships that could be construed as a potential conflict of interest.

Copyright (c) 2016 Requejo and McNitt-Gray. This is an open-access article distributed under the terms of the Creative Commons Attribution License (CC BY). The use, distribution or reproduction in other forums is permitted, provided the original author(s) or licensor are credited and that the original publication in this journal is cited, in accordance with accepted academic practice. No use, distribution or reproduction is permitted which does not comply with these terms. 